\title{
Factores de éxito en el financiamiento para Pymes a través del Crowdfunding en México
}

\author{
John de Jesús González ${ }^{1}$ - Universidad Autónoma del Estado de México, México \\ Filiberto Enrique Valdés Medina² - Universidad Autónoma del Estado de México, México \\ María Luisa Saavedra García ${ }^{3}$ - Universidad Nacional Autónoma de México, México \\ Mención Honorifica, Categoría investigación financiera empresarial \\ XXXV Premio Internacional de Investigación Financiera IMEF-EY 2019
}

Esta investigación tiene como objetivo identificar las variables que impactan el éxito de financiamiento de las Pymes que participan en Crowdfunding, para lo cual, se aplicó un análisis de covarianza (Ancova) a una muestra empresas que obtuvieron financiamiento a través de la plataforma de fondeo colectivo Pitchbull. Los resultados muestran que el riesgo impacta significativamente el éxito de fondeo, resultando además ser covariables relevantes: la tasa de interés pagada, el monto financiado, y el número de fondeadores, no siendo el caso para el plazo del crédito pues es una covariable poco significativa. Del análisis del éxito de fondeo y su relación con el riesgo, se destaca la tasa de retorno como principal incentivo en el fondeo de las empresas. Aun cuando la principal limitación de este trabajo es el análisis de una sola plataforma, estos hallazgos representan un punto de partida para futuros trabajos relativos al análisis de las implicaciones de las finanzas tecnológicas en las Pymes, sin embargo, resta profundizar las investigaciones desde el impacto ético, social, y ambiental en las decisiones de fondeo.

Clasificación JEL: G29, G32.

Palabras clave: Crowdfunding, financiamiento, PYME, Fintech.

\section{Success Factors in Financing for Smes Through Crowdfunding in Mexico}

This research aims to identify the variables that impact the financing success of SMEs that participate in Crowdfunding, for which, a covariance analysis (Ancova) was applied to a sample of companies that obtained financing through the collective funding platform Pitchbull. The results show that risk has a significant impact on funding success, also turning out to be relevant covariates: the interest rate paid, the amount financed, and the number of funders, not being the case for the term of the loan as it is an insignificant covariate. From the analysis of the funding success and its relationship with risk, the rate of return stands out as the main incentive in funding companies. Although the main limitation of this work is the analysis of a single platform, these findings represent a starting point for future work related to the analysis of the implications of technological finance in SMEs, however, it remains to deepen the research from the impact ethical, social, and environmental in funding decisions.

JEL Classification: G29, G32.

Keywords: Crowdfunding, financing, SMEs, Fintech.

1 ORCID: http://orcid.org/0000-0003-0681-7313

2 ORCID: http://orcid.org/0000-0003-1424-1465

${ }^{3}$ Autor de correspondencia, ORCID: http://orcid.org/0000-0002-3297-1157

*Sin fuente de financiamiento para el desarrollo de la investigación. 


\section{Introducción}

Las Finanzas tecnológicas o Fintech representan un conjunto de empresas con fuertes componentes de innovación y tecnología revolucionando los servicios financieros actuales logrando mejoras en la calidad y una drástica disminución de costos. Por otro lado, las pequeñas y medianas empresas o Pymes presentan un abanico de problemáticas para mantenerse vigentes en un medio cambiante y hostil que limita su supervivencia; de los diversos retos que afrontan destacan las limitadas opciones de financiamiento, fuentes tradicionalmente operadas por el sistema financiero formal el cual considera el financiamiento a las Pymes como operaciones con un alto nivel de riesgo, debido en gran medida a la alta tasa de mortandad que presentan, y como operaciones con alto costo debido al gran volumen de empresas necesarias para mantener sus márgenes de beneficio al tener que atender a un gran número de empresas; por esta razón el surgimiento de modelos disruptivos como el fondeo colectivo (crowdfunding) surge como una nueva alternativa que permite que integrantes de la sociedad (personas físicas y morales) funjan como inversionistas particulares, colocando sus recursos excedentes en el fondeo de iniciativas empresariales bajo condiciones menos rígidas en comparación con la banca tradicional.

Las pequeñas y medianas empresas (Pymes) son indispensables en el desarrollo social de las naciones, un aspecto destacable es su alto índice de empleabilidad (Sánchez et al., 2004), según datos oficiales publicados por INEGI (2015) el 99.8\% de las unidades económicas en México son Pymes mismas que aportan el 52\% del Producto Interno Bruto (PIB) y generan el 71\% del empleo. Por otro lado, la falta de financiamiento es la principal dificultad que afrontan las pequeñas y medianas empresas (Pymes) en México (Cohen y Baralla, 2012; OCDE-CEPAL, 2012), en este sentido el 40\% de las empresas no crece por falta de crédito, y el 60\% de las empresas en México no puede aceptar un crédito bancario debido a su alto costo (INEGI, 2015), ante esta problemática las finanzas tecnológicas en lo general, y las empresas de fondeo colectivo en lo particular representan una alternativa de solución. A nivel mundial se estima que existen poco más de 8,800 empresas Fintech, México cuenta con un $22.3 \%$ de estas empresas, de las cuales, 29 pertenecen al segmento crowdfunding (7.4\%), 81 al segmento préstamos (20.6\%) y el $72 \%$ restante a otros segmentos de acuerdo con la información proporcionada por Finnovista (2019). Así pues, durante 2017, en México cerca de 8,000 empresas consiguieron financiamiento bajo la modalidad de deuda y capital, mientras que poco más de 1,500 empresas consiguieron financiamiento bajo la modalidad de crowdfunding no financiero (CONAIF, 2018). En este sentido, México es uno de los líderes en empresas Fintech en Latinoamérica, superado solamente por Brasil que tiene el 32.7\%, mientras México agrupa el 25.6\% de las Fintech de la región, seguido de lejos por Colombia que ostenta el 11.9\%; de ahí la importancia de realizar este estudio (Startupbootcamp, EY, IPADE, 2019)

Por lo anterior, este trabajo tiene como objetivo identificar los principales factores de éxito de financiamiento a través de Crowdfunding en Pymes, que permita el desarrollo de emprendimientos en el país. Por lo cual, se evaluó el impacto de variables como el tiempo de fondeo (éxito de financiamiento), calificación de riesgo, monto de crédito, plazo, tasa de interés, y número de fondeadores, en el éxito de financiamiento de las entidades en busca de fondos, considerando la plataforma de fondeo colectivo Pitchbull. 


\section{Revisión de la literatura}

\subsection{El financiamiento de la Pyme en México}

Estudios antecedentes refieren que las empresas mexicanas en general cuentan con acceso limitado al financiamiento bancario; esta problemática adquiere mayores dimensiones en el caso de las Pyme, ente productor esencial en la economía (Fenton \& Padilla, 2012; Saavedra \& Saavedra, 2016; Banco de México, 2014). Las razones de este obstáculo son variadas, desde las atribuidas a las fallas de mercado (Goldstein, 2011), tasas de interés elevadas e incumplimiento de requisitos ante las instituciones (Saavedra, Milla, \& Sánchez, 2012), monto exigido como colateral, la falta de información confiable acerca de las Pymes a la que se enfrentan los oferentes, los altos índices de mortandad, la baja productividad, la informalidad (Banco de México, 2015), trámites burocráticos y garantías (Martínez, Pérez de Lema, \& Hernández, 2008). Los empresarios que no acceden a créditos de intermediarios financieros financian sus negocios principalmente con capital propio y el crédito otorgado por proveedores siendo éste utilizado por más del 60\% de las Pymes (Pavón, 2010), otras fuentes de capital son amistades, familiares y productos de crédito al consumo o microcréditos que comúnmente se ofertan y otorgan a personas físicas (Bruhn \& Love, 2014; León \& Saavedra, 2018).

En México, el número de Pymes registradas al 2015 (INEGI) fue de 16,754 empresas medianas, 79,367 empresas pequeñas y 3'952,422 empresas micro de las cuales el 39.8\%, 27.8\% y $10.6 \%$ respectivamente obtuvieron financiamiento mediante el sistema financiero tradicional, mientras que el $60.2 \%$ de empresas medianas, el $72.20 \%$ de empresas pequeñas y el $89.40 \%$ no contó con ningún tipo de financiamiento. Con crédito de proveedores se financiaron $40.3 \%$ de las empresas medianas, $38.1 \%$ de las empresas pequeñas, y $12.4 \%$ de las microempresas. Así mismo se utilizan los recursos propios como alternativa de financiamiento por lo que el $16.7 \%$ de las empresas medianas, 24.3\% de las empresas pequeñas y el 28.7\% de las microempresas utilizaron esta opción (Banco de México, 2015).

Las Pymes mexicanas no tienen las mismas ventajas de acceso a fuentes de financiamiento como las que se presentan en otros países de América Latina, al contrario, en el país se presenta un importante rezago en el contexto del crédito que se otorga al sector privado. Un estudio del Banco Mundial (2017), pone en evidencia esta problemática en México, revela que el crédito interno al sector privado como porcentaje del PIB en México solo alcanzó el 32.49\% al cierre de 2015 con un crecimiento del $2.54 \%$ para el cierre de 2016, evidentemente por debajo del crédito que otorgan al sector privado países como Chile que registró 112\%, Brasil 62.19\%, Costa Rica 59.26\% o Panamá $89.40 \%$ al cierre del mismo año, denotando el impulso que se le da en estos países a este sector medular de la economía.

\subsection{Finanzas Tecnológicas}

México es uno de los líderes de la innovación financiera en América Latina, en conjunto con Brasil y Colombia. Los ecosistemas Fintech de estos Hubs están en crecimiento y desarrollo constante. De acuerdo con datos de Finnovista \& BID (2019), en un comparativo de los segmentos Fintech de estas tres regiones, comparten con variaciones mínimas 3 segmentos principales: pagos y remesas, 
préstamos y gestión de finanzas empresariales. El segmento de pagos y remesas se posiciona como el de mayor importancia y crecimiento en los tres países, lo que evidencia una permeación de gran importancia de la tecnología móvil y su uso. México es el principal actor en el segmento de fondeo colectivo, indicativo de una fuerte aceptación por parte de la comunidad inversionista en comparación con Brasil y Colombia. En la gráfica 1, se muestran las comparaciones por segmentos de los tres principales Fintech Hubs en la región por número de empresas.

\subsection{Fintech México}

México cuenta con 394 startups Fintech, de las cuales un 7.4\% corresponden a fondeo colectivo, el $40.7 \%$ pertenecen a los segmentos de préstamos, pagos y remesas, y el $51.9 \%$ pertenecen a diversos sectores como la gestión de finanzas empresariales (EFM), la gestión de finanzas personales (PFM), tecnologías empresariales para instituciones financieras (ETFI), seguros, puntaje, identidad y fraude, bancos digitales, trading y mercados de capitales, y gestión patrimonial, en cuanto a su ubicación la mayoría de startups FinTech mexicanas se han desarrollado en la Ciudad de México (60\%), Guadalajara (9\%), Monterrey (6\%), Mérida (4\%), Puebla (2\%) y el 18\% restante en otras ciudades del país (Finnovista, 2019). El ecosistema FinTech mexicano es joven, pues un 85\% está conformado por startups con 5 años o menos de actividad y solo un 15\% con más de 5, un 83\% de estas empresas opera a nivel nacional y un $17 \%$ internacionalmente. Por otro lado, es imperante resaltar que el ecosistema Fintech mexicano en concordancia con las regulaciones que la Ley de Instituciones de Tecnología Financiera, requiere que los participantes, en particular los del segmento crowdfunding, obtengan un registro ante la CNBV para fungir como intermediarios. Algunas empresas de este segmento ya han iniciado su formalización, pero en general, la falta de experiencia en el proceso regulatorio y los altos costos son los obstáculos principales para cumplir con el requerimiento y poder fungir como Instituciones de Tecnología Financiera (ITF), es posible que por estas razones algunas empresas cierren operaciones y otras, en su defecto, sean absorbidas por entidades de mayor capacidad en un futuro.

\subsection{El crowdfunding en México}

El fondeo colectivo representa el esfuerzo individual de una base comunitaria que conecta y suma su dinero a través de plataformas especializadas en internet para apoyar los esfuerzos iniciados por otras personas u organizaciones (Ordanini, Miceli, Pizzetti, \& Parasuraman, 2011; Ballell, 2013) BBVA (2016) menciona que el crowdfunding es un fenómeno de desintermediación financiera por la cual se ponen en contacto promotores de proyectos que buscan obtener fondos a través de emisión de valores o solicitudes de préstamos con inversionistas. El crowdfunding a nivel internacional puede clasificarse en 4 grupos: de capital, de donación, de recompensa y de préstamos.

El fondeo colectivo de capital ofrece a los inversionistas acciones de la empresa a cambio de su inversión, teniendo dos vertientes el liderado por el inversionista y el liderado por la compañía de manera similar a aquellas que intermedian títulos de renta fija (Cuesta et al., 2014), por otro lado, el fondeo colectivo de donación (Donation based crowdfunding) busca recaudar fondos para proyectos 
sociales o culturales, se fundamenta en las aportaciones de los participantes como donaciones, para apoyar, sin fines de lucro aquellos proyectos respaldados por organizaciones no gubernamentales; en el fondeo colectivo de recompensa (Reward based crowdfunding) los usuarios aportan cantidades económicas de tamaño variable a un proyecto en específico a cambio de lo que comúnmente se califica como recompensa que legalmente funciona como un contrato de compraventa (Rodríguez, 2013), y el fondeo colectivo de préstamos (Lending o debt based crowdfunding) donde el financiamiento se obtiene a partir de operaciones de préstamos que provienen de los prestamistas y los promotores del proyecto que buscan fondeo, la contraprestación que recibe el prestamista es un tipo de premio o interés sobre la cantidad inicialmente otorgada. Actualmente en México la Ley de Instituciones de Tecnología Financiera reconoce legalmente las operaciones de fondeo colectivo en las modalidades de: deuda, capital, y copropiedad o regalías, quedando el fondeo colectivo de donaciones en un marco legal diferente (DOF, 2018).

Dentro de las ventajas del fondeo colectivo en Pymes destacan la facilidad y relativa sencillez para lograr el fondeo, tasas de interés más competitivas, e inclusive permite la captación de los primeros clientes. Por otro lado, al financiador le permite participar en iniciativas de negocio innovadoras, con montos accesibles y a distintos niveles de riesgo. Dentro de las desventajas del financiado se tiene que muchas veces es difícil fondear la totalidad del proyecto en los tiempos establecidos si el monto a financiar es elevado, además del riesgo que implica hacer pública la idea de negocio, por otro lado, el financiador tiene la posibilidad de lograr resultados poco satisfactorios e incumplimiento, y en casos extremos incluso fraude por parte de los financiados. Entre otros aspectos existen riesgos que son inherentes al fondeo colectivo, los cuales se describen en la tabla 1.

Tabla 1. Riesgos del fondeo colectivo

\begin{tabular}{|l|l|}
\hline Riesgo & Descripción \\
\hline $\begin{array}{l}\text { me } \\
\text { mercado }\end{array}$ & $\begin{array}{l}\text { El riesgo de una probable pérdida dentro de un plazo en particular en el valor de un } \\
\text { instrumento o portafolio financiero producto de cambios en las variables de } \\
\text { mercado, como tasas de interés, tasas de cambio de moneda, spreads de crédito }\end{array}$ \\
\hline De liquidez & $\begin{array}{l}\text { Uno de los mayores riesgos financieros en las operaciones tradicionales y P2P (Peer } \\
\text { to Peer) ha estado asociado al hecho de que una de las partes de la operación } \\
\text { financiera no pueda obtener la liquidez necesaria para asumir sus obligaciones con } \\
\text { el depositante. }\end{array}$ \\
\hline $\begin{array}{l}\text { De } \\
\text { solvencia }\end{array}$ & $\begin{array}{l}\text { En las operaciones P2P este tipo de riesgo se puede ver agravado por una mayor } \\
\text { asimetría de información entre emprendedores e inversionistas. }\end{array}$ \\
\hline De crédito & $\begin{array}{l}\text { Posible efecto negativo que generaría a la entidad prestamista una variación en las } \\
\text { condiciones y plazos de un contrato. }\end{array}$ \\
\hline Operativo & $\begin{array}{l}\text { Se refiere a la posibilidad de sufrir pérdidas por fallos en los procesos, en la } \\
\text { información, en los sistemas internos de la plataforma, así como pérdidas }\end{array}$ \\
\hline
\end{tabular}

${ }^{4}$ De acuerdo con la definición de JP Morgan https://www.jpmorgan.com/jpmpdf/1320703360326.pdf 


\begin{tabular}{|l|l|}
\hline & $\begin{array}{l}\text { ocasionadas por errores humanos o por las consecuencias de sucesos ajenos a la } \\
\text { operación. }\end{array}$ \\
\hline Legal & $\begin{array}{l}\text { En México existe una sólida regulación para las instituciones de tecnología } \\
\text { financiera de financiamiento colectivo, operaciones con activos virtuales y para } \\
\text { pagos electrónicos. }\end{array}$ \\
\hline
\end{tabular}

Elaboración propia con información del Centro de Innovación BBVA (2015).

\subsection{Plataforma de financiamiento colectivo para Pymes Pitchbull}

La plataforma objeto de estudio es Pitchbull que se especializa en préstamos para Pymes por medio de levantamiento de capital fondeado colectivamente, maneja tasas desde el $11 \%$ anual, considerando montos que van de los 100,000 - $\$ 1,000,000$ pesos sin garantía prendaria ni hipotecaria, en plazos de 6 a 24 meses, al 2019 ha realizado la colocación de \$94,314,910 pesos mexicanos (Pitchbull, 2019). Los préstamos son financiados directamente por personas a través de un mercado que opera mediante una plataforma en internet, así mismo los préstamos solicitados son utilizados para dos propósitos, los relativos al financiamiento de capital de trabajo, o adquisición de activo fijo y equipamiento. El tiempo destinado al levantamiento de capital de cualquier proyecto aceptado es de 21 días con posible prórroga, los datos muestran evidencia de tiempos de 18 segundos para completar exitosamente el monto solicitado.

\section{Método}

La presente investigación corresponde a un estudio no experimental, mixto, puesto que se analizaron variables tanto cuantitativas como cualitativas (ver tabla 2), con alcance descriptivo, correlacional y causal. Las variables de tipo cuantitativo son: éxito de financiamiento (tiempo de fondeo), monto, plazo, tasa de interés ofertada para inversionistas y número de fondeadores. La variable de tipo cualitativo es: la calificación de riesgo de la empresa solicitante. La variable dependiente es decir el éxito de financiamiento será medida por el tiempo que transcurre entre la solicitud del capital y su obtención; las variables independientes son: la calificación del riesgo, monto recabado, la tasa de interés ofertada a los fondeadores, plazo, el número de fondeadores. Los datos fueron recuperados de la plataforma Pitchbull y corresponden a un período de tres años, la frecuencia del levantamiento del capital se midió en horas, estudiando 145 casos. El análisis de datos de las variables se realizará mediante la técnica de análisis estadístico multivariante Ancova o análisis de la covarianza haciendo uso del software estadístico IBM SPSS, PC.

Las series de datos se compone de 115 observaciones (sin datos perdidos), que corresponden al total de créditos fondeados con éxito a lo largo de 3 años, la variable dependiente corresponde al tiempo de fondeo, es de escala de razón, y esta expresada en horas de fondeo, la variable independiente es el nivel de riesgo con el que se oferta cada proyecto, es de escala ordinal con 4 tipos de riesgo (A1,A2,B1, y B2) donde $\mathrm{A} 1$ son los proyectos de menor riesgo, y $\mathrm{B} 2$ representan los proyectos de mayor riesgo. Las series de datos de las covariables son: la de tasa de interés, registrada 
en escala de razón, y se modelo en decimales, el plazo de crédito de escala de razón y modelada en días, el monto de crédito expresado en escala de razón, y modelada en miles de pesos, y el número de fondeadores que representa las personas que aportaron fondos para financiar las iniciativas de emprendimiento (ver tabla 2).

La hipótesis de investigación es:

$\mathrm{H}_{1}$ : Existen diferencias significativas en el éxito de financiamiento de los proyectos publicados en la plataforma de fondeo colectivo Pitchbull, en función de la calificación de riesgo controlando el monto del crédito solicitado, el plazo, la tasa y el número de fondeadores de las empresas solicitantes de capital.

De la que se desprende la hipótesis nula:

$\mathrm{H}_{01}$ : No existen diferencias significativas en el éxito de financiamiento de los proyectos publicados en la plataforma de fondeo colectivo Pitchbull, en función de la calificación de riesgo controlando el monto del crédito solicitado, el plazo, la tasa y el número de fondeadores de las empresas solicitantes de capital.

Tabla 2. Definición y operacionalización de las variables

\begin{tabular}{|c|c|c|c|c|c|}
\hline Variable & Tipo & $\begin{array}{l}\text { Medición/ } \\
\text { Escala }\end{array}$ & Autor & Definición conceptual & Operacionalización \\
\hline $\begin{array}{l}\text { Éxito de } \\
\text { financia- } \\
\text { miento } \\
\text { (tiempo } \\
\text { de } \\
\text { fondeo) }\end{array}$ & Cuantitativa & $\begin{array}{l}\text { Intervalo: } \\
\text { Horas }\end{array}$ & $\begin{array}{l}\text { Pitcbull, } \\
2019\end{array}$ & $\begin{array}{l}\text { Tiempo que transcurre desde el } \\
\text { momento en que se publica un } \\
\text { proyecto hasta el levantamiento } \\
\text { total del capital meta. En la } \\
\text { plataforma de fondeo colectivo } \\
\text { Pitchbull el periodo máximo es de } \\
21 \text { días con la reserva de la } \\
\text { empresa intermediaria a } \\
\text { prorrogar este tiempo. }\end{array}$ & $\begin{array}{l}\text { Tiempo transcurrido de } \\
\text { levantamiento de capital } \\
\text { (Tiempo de fondeo). }\end{array}$ \\
\hline $\begin{array}{l}\text { Cal. de } \\
\text { Riesgo }\end{array}$ & Cualitativa & $\begin{array}{l}\text { Ordinal } \\
\text { Parámetros: } \\
\text { A1 } \\
\text { A2 } \\
\text { B1 } \\
\text { B2 }\end{array}$ & $\begin{array}{l}\text { Venegas- } \\
\text { Martínez, } \\
\text { 2013; Joseph, } \\
2013\end{array}$ & $\begin{array}{l}\text { Se recopila información de la } \\
\text { empresa evaluada en temas } \\
\text { económicos y financieros, luego } \\
\text { entonces, se estima la } \\
\text { probabilidad de incumplimiento } \\
\text { con una calificación como } \\
\text { indicador de su solvencia. } \\
\text { Una vez completado el proceso de } \\
\text { evaluación de crédito se le asigna } \\
\text { una calificación al prestatario, el } \\
\text { cual denota el grado de riesgo de } \\
\text { impago asociado al solicitante. }\end{array}$ & $\begin{array}{l}\text { Calificación de riesgo otorgada } \\
\text { por Pitchbull a la empresa } \\
\text { solicitante. } \\
\text { A1: La mejor combinación de } \\
\text { récord crediticio. Probabilidad } \\
\text { de incumplimiento mínima. } \\
\text { A2: Combinación robusta de } \\
\text { récord crediticio, Probabilidad } \\
\text { de incumplimiento muy baja. } \\
\text { B1: Combinación fuerte de } \\
\text { récord crediticio, Probabilidad } \\
\text { de incumplimiento baja. } \\
\text { B2: Combinación suficiente de } \\
\text { récord crediticio, Probabilidad } \\
\text { de incumplimiento moderada. }\end{array}$ \\
\hline Monto & Cuantitativa & $\begin{array}{l}\text { Razón } \\
\text { Pesos }\end{array}$ & $\begin{array}{l}\text { Villaobos, } \\
2012 ; \\
\text { Brighi \& } \\
\text { Venturelli, } \\
2017\end{array}$ & $\begin{array}{l}\text { Es el capital requerido por la } \\
\text { empresa que se está fondeando. } \\
\text { Importe total del crédito } \\
\text { solicitado. }\end{array}$ & $\begin{array}{l}\text { Cantidad de dinero requerida } \\
\text { por la empresa solicitante. }\end{array}$ \\
\hline
\end{tabular}




\begin{tabular}{|c|c|c|c|c|c|}
\hline Plazo & Cuantitativa & $\begin{array}{l}\text { Intervalo } \\
\text { Horas }\end{array}$ & $\begin{array}{l}\text { Camacho \& } \\
\text { Delgado, } \\
1996\end{array}$ & $\begin{array}{l}\text { "Un hecho futuro y cierto, del cual } \\
\text { depende la ejecución o extinción } \\
\text { de una obligación. Son dos las } \\
\text { características del plazo, su } \\
\text { ocurrencia futura y su certeza" (p. } \\
\text { 101). }\end{array}$ & $\begin{array}{l}\text { Tiempo de duración del } \\
\text { contrato del préstamo. }\end{array}$ \\
\hline Tasa & Cuantitativa & $\begin{array}{l}\text { Razón } \\
\text { Porcentaje }\end{array}$ & Soto, 2001 & $\begin{array}{l}\text { Porcentaje que se aplica a una } \\
\text { cantidad monetaria que } \\
\text { denominamos capital y que } \\
\text { equivale al monto que debe } \\
\text { cobrarse o pagarse por pedir } \\
\text { dinero prestado o en palabras más } \\
\text { simples es un porcentaje, que da } \\
\text { lugar a un rendimiento después de } \\
\text { transcurrido un plazo. }\end{array}$ & $\begin{array}{l}\text { Tasa anual ofertada de un } \\
\text { proyecto en particular para } \\
\text { inversionistas. }\end{array}$ \\
\hline $\begin{array}{l}\text { No. de } \\
\text { fondeado } \\
\text { res }\end{array}$ & Cuantitativa & $\begin{array}{l}\text { Razón } \\
\text { Número }\end{array}$ & $\begin{array}{l}\text { Rodríguez, } \\
2016\end{array}$ & $\begin{array}{l}\text { En el fondeo colectivo del tipo peer } \\
\text { to peer se pone en contacto a } \\
\text { inversionistas con personas que } \\
\text { buscan la obtención de algún } \\
\text { crédito, los inversionistas } \\
\text { adquieren un instrumento de } \\
\text { deuda a través del cual reciben } \\
\text { una tasa de interés fija y el } \\
\text { reembolso de su capital en un } \\
\text { plazo determinado. }\end{array}$ & $\begin{array}{l}\text { Total de inversionistas de un } \\
\text { proyecto en particular. }\end{array}$ \\
\hline
\end{tabular}

Fuente: Elaboración propia a partir de diversos autores.

En referencia a la variable calificación de riesgo (tabla 2), es evaluada con metodología propia de Pitchbull la cual considera la información proporcionada del solicitante, análisis de riesgos (legal, financiero, cualitativo), información de buró de crédito y bases jurídicas. El resultado define la calificación de riesgo del préstamo (A1, A2, B1, B2), la tasa fija de interés anual ofertada a los fondeadores es asignada por la empresa (8\% al 18\%) para cada plazo disponible $(6,12$ y 18 meses) de acuerdo con el nivel de riesgo.

A continuación, se realizará un análisis conceptual de las variables utilizadas en este estudio.

La calificación de Riesgo de acuerdo a Koulafetis (2017), es un conjunto de opiniones sobre el riesgo crediticio relativo que son realizadas por las Agencias de Calificación; por su parte Standard and Poor's (2014) menciona que las calificaciones crediticias expresan la opinión de la calificadora sobre la capacidad y voluntad de un deudor, que puede ser una empresa, institución financiera, estado o municipio para cumplir con sus obligaciones financieras en tiempo y forma; mientras que HM Treasury (2004) define a la calificación del riesgo como un enfoque mediante el cual cada nivel y parte de la organización, revisa sus actividades y contribuye con su diagnóstico de los riesgos que enfrenta. El riesgo crediticio en palabras de Romanyuk (2016, citado en Brown (2008, p.16) es una tasa de préstamo, y un período de préstamo que se pueden perder en un incumplimiento. El potencial que una parte contractual no podrá cumplir con sus obligaciones de conformidad con los términos acordados. Así mismo, de acuerdo con Fiedler (1971) el riesgo crediticio es la probabilidad de que un préstamo no sea pagado de acuerdo con los términos del contrato. Así mismo, Sydbank Group (2017) lo define como el riesgo de pérdida resultado del incumplimiento por los clientes y otras contrapartes 
obligadas de pago en los préstamos, anticipos de crédito, compromisos y garantías, así como de valores de mercado y derivados.

Schreiner (2001) por su parte, define el monto del préstamo como el equivalente en la cantidad desembolsada en el saldo promedio, y el tiempo entre cuotas. Asimismo, Jacoby, et. al. (1942) refiere que es una forma de crédito comercial conformado por un crédito extendido, una relación directa entre prestatario y prestamista; y la provisión al momento que se reembolsa después de un lapso. Jiménez y Saurina (2002) mencionan que el monto del préstamo, que en la mayoría de los casos está directamente relacionado con el tamaño del prestatario, la edad de la empresa, o la edad de la duración de la relación banco-prestatario. El importe del crédito de acuerdo con Cole, et. al. (2004) es la cantidad del préstamo solicitado, mientras que Villalobos (2012) menciona que el monto del crédito describe el monto total que un prestatario está autorizado a pedir prestado. Los montos máximos de préstamos se utilizan para préstamos estándar, tarjetas de crédito y cuentas de línea de crédito.

De acuerdo con Mota et al. (2018), la duración del préstamo es el periodo de tiempo que da certeza a la probabilidad de devolver el importe total del préstamo, por su parte Otieno (2015) menciona que la duración del préstamo se define como el pago regular durante un periodo de tiempo de un préstamo, así bien Villalobos (2012) refiere que la duración de un préstamo está dada por un cronograma de pago específico y una tasa de interés fija o variable. Por su parte Atieno (2001) define al plazo del crédito como la garantía, periodo de reembolso y tasas de interés a los préstamos, mientras que Edwards (2004) sugiere que los términos de un crédito son el centro de un contrato que abarcan el beneficio planificado, la necesidad de efectivo y la situación competitiva; por su parte Cuñat \& García-Appendini (2012) concluyen que son las condiciones de crédito ofrecidas por el prestador, que les permiten a los prestatarios conocer el tiempo límite del pago del crédito.

La tasa de interés se puede definir como la compensación recibida por diferir el consumo, o el costo equivalente de consumo antes de adquirir los activos necesarios, las tasas de interés pueden ser consideradas como el equilibrio del precio del dinero (Bean, 2017). A menudo se expresa como un porcentaje del monto prestado (principal) por un año o cualquier otro período de tiempo, y es utilizada por los bancos al asumir el riesgo de realizar préstamos (Smith \& Smith, 2000).

Los fondeadores pueden definirse como los actores necesarios de los cuales dependen las condiciones y el nivel de financiamiento inicial, incluyendo factores como el mercado (Capizzi \& Carluccio (2016), también se refieren a ellos como una persona o una entidad que desembolsa recursos financieros (Penna, 2011; De Vincentiis, Culasso \& Cerrato, 2019), así como individuos que buscan diversificar su portafolio al ingresar nuevos y diferentes activos poco correlacionados entre ellos, al proveer pequeñas sumas de dinero a un número dado de proyectos (Previati, Galloppo \& Salustri, 2015) . Por otra parte, Chandler (2016) y Chen (2010) mencionan que el tamaño de los activos es el valor de mercado de los valores en una cartera de fondos mutuos o fondo individual, mientras que Chen (2010) también son llamados activos bajo gestión.

En los siguientes párrafos se presentan los hallazgos relativos a la revisión de la literatura relativos a las variables utilizadas para el presente trabajo:

- Calificación de Riesgo. El análisis de la calificación de riesgo de crédito corporativo consiste en evaluar los factores que son comunes en todos los sectores, como la propiedad, la gestión, la estructura corporativa, la liquidez, el gobierno, los riesgos relacionados con el país y los factores 
que pueden ser útiles para una empresa en particular (Koulafetis, 2017). La calificación de riesgo es muy importante pues estudios antecedentes han encontrado una relación positiva entre los préstamos otorgados y un perfil de riesgo-rentabilidad favorable para la banca (Capizzi \& Carluccio, 2016). Por otra parte. Ekpu (2016) considera la calificación crediticia, y el número de impagos como medida de riesgo, ajustada a los requisitos de garantía de los bancos, en la misma línea Chan \& Kanatas (1985) mencionan que las garantías pueden utilizarse como señal de alta calidad crediticia, mientras que Besanko y Thakor (1987) encuentran que la garantía juega un papel útil a la hora de determinar el riesgo crediticio.

- $\quad$ Riesgo Crediticio. Cahn, Girotti \& Salvadè (2018) encontraron que cuanto más alta sea la puntuación de riesgo crediticio, la probabilidad de incumplimiento será mayor, también mencionan que las calificaciones crediticias son vitales para las pequeñas y medianas empresas en la obtención de financiamiento. Por su parte Nesta (2014) menciona que las calificaciones crediticias colocan a los solicitantes en categorías que les permiten obtener créditos con mayor facilidad, siendo este uno de los factores clave para explicar por qué las plataformas de crédito P2P tienen una tasa de morosidad media y ponderada muy baja. Así mismo las calificaciones crediticias de las pequeñas y medianas empresas contribuyen a reducir la brecha de información entre los bancos. Las calificaciones externas disminuyen el poder de los prestamistas tradicionales y aumentan la competencia bancaria, este aumento de la competencia difiere del inducido por el uso de la calificación crediticia, o más ampliamente, por el progreso tecnológico (Hauswald \& Márquez, 2003; Berger et al., 2002; Sutherland, 2018). Por otro lado, Berger et al. (2002), encontraron que una disminución en la puntuación de crédito resaltaría un deterioro de la solvencia pudiendo dificultar la obtención de un crédito

- Monto del Préstamo. El monto del préstamo está altamente correlacionado al tamaño de la empresa sujeta al mismo, por ende, las empresas que están en la fase de idea o conceptual obtienen montos relativamente pequeños en sus etapas de arranque (Capizzi \& Carluccio, 2016), de esta manera el racionamiento del crédito a las Pyme puede tomar dos formas, la primera consiste en que algunos prestatarios no obtienen ningún préstamo aunque pueden tener proyectos de inversión rentables, y la segunda implica el racionamiento del monto solicitado, que consiste en otorgar una cantidad inferior a la solicitada por el prestatario (Stiglitz \& Weiss, 1981; Jaffee \& Russell,1976; Brighi \&Venturelli, 2017), de esta forma el tamaño del crédito está relacionado a la cuantía de las garantías prueba de ello es el estudio de Jiménez, et al. (2006) quienes encontraron una relación positiva entre el tamaño del préstamo y la probabilidad de solicitar garantías a las pequeñas y medianas empresas.

- Duración del préstamo. La duración del préstamo se refiere al tiempo de reposición de los fondos obtenidos de las entidades que fungen como prestatarias. Los tipos créditos para las pequeñas y medianas empresas pueden ser a plazos (o tasa fija) o a tasa variable, un crédito a plazos considera pagos mensuales fijos eliminando las variaciones entre un mes y otro (Onyango, 2010), en un análisis realizado por Benchimol (2013), encontró que los préstamos a plazo tienen una duración entre uno y diez años, aunque algunos casos pueden durar hasta 30 años. En el caso particular de las pequeñas y medianas empresas Signoriello (1991) encontró que la duración del préstamo se puede dar de forma individual, en cuanto a la duración del préstamo, los créditos a 
largo plazo son más convenientes para las empresas nuevas o en expansión, ya que se supone que aumentarán sus beneficios con el tiempo. En México el plazo de préstamo para las Pyme va de entre uno a diez años (Vite \& Saavedra, 2018).

- Tasa de Interés. La tasa de interés es uno de los factores más importantes en el análisis de los créditos, Moro, et al. (2017) mencionan que altas tasas de interés reducen el número de solicitudes de préstamos, por su parte Brighi \& Venturelli (2017) encontraron una fuerte relación positiva entre los periodos alcistas y bajistas de las tasas de interés, y la cantidad de crédito solicitado por las empresas, de esta forma si el costo del crédito aumenta, la demanda de préstamos bancarios disminuye, y viceversa. Por otra parte, el monto de la garantía prendaria de un préstamo está relacionada con las tasas de interés, de modo que las garantías solicitadas serán mayores cuando el préstamo se otorga en un período de tasas de interés reales más altas (Boot, et al., 1991 y Jiménez et al., 2006).

- Número de Fondeadores. El número de fondeadores representa el eje fundamental del fondeo colectivo, ya que en esta variable junto con la tecnología descansa el modelo de negocios; con el crowdfunding un emprendedor puede conseguir una gran financiamiento de un público muy extenso en el cual cada uno aporta una pequeña parte del financiamiento total, en vez de solicitar una pequeña cantidad de inversionistas sofisticados (Calvo,\& Jacynycz, 2015), por ende el fondeo colectivo se sustenta en la cantidad de fondeadores que participan de las diversas iniciativas, por ejemplo Kickstarter ${ }^{5}$ ha permitido el acceso al financiamiento de 173.475 proyectos, por un monto total de \$4.663.603.000 mdd, con la participación de 17.153.882 fondeadores a nivel global (Kickstarter, 2019). La importancia de los fondeadores es tal que Quero, et al. (2014) en su análisis de las relaciones de co-creación de valor en plataformas de fondeo colectivo, concluye que el diseño de un proyecto de crowdfunding debería centrarse en satisfacer el interés de inversionistas o, en su caso, consumidores cuyo comportamiento se corresponda con una pre-compra del producto.

- Tamaño de la empresa. En lo relativo al tamaño de la empresa y la obtención de crédito en México está ampliamente documentado el pobre acceso al crédito de las micros, pequeñas y medianas, el crédito total a las microempresas en 2015 fue alrededor de 140 mil millones de pesos dividido en poco más de 200000 empresas, en contraste con 1,100 mil millones de pesos asignados entre 4,000 grandes empresas (Herman \& Kemmel 2017, 6 citado en Martínez, 2018, 19), en concordancia con lo anterior Brighi \& Venturelli (2017) sugieren que cuanto mayor sea el tamaño de la empresa, mayor será la demanda de crédito; además, cuanta más pequeña sea la empresa, más grave será el problema del racionamiento del crédito, en cuanto a dicha problemática, para Martínez $(2018,26)$ la informalidad, la baja productividad, y la menor supervivencia de las empresas de menor tamaño podrían ser causa, pero también consecuencia de la falta de acceso al crédito.

\footnotetext{
${ }^{5}$ Kickstarter, es una plataforma que opera financiamiento para proyectos creativos.
} 


\section{Resultados}

En la primera parte se presentan los resultados para validar los supuestos previos al análisis de la covarianza, seguido por el análisis de los resultados del modelo aplicado al conjunto de variables. Las empresas objeto de estudio son todas las que solicitaron financiamiento desde la apertura de la institución de tecnología financiera hasta el mes de junio de 2018, con un total de 145 casos con financiamiento exitoso, contando con la misma cantidad de datos por cada variable.

\subsection{Validación se supuestos del análisis de la covarianza 4.1.1Prueba de homogeneidad de la varianza (Levene's Test)}

La prueba de homogeneidad de la varianza se llevó a cabo con la prueba de Levene la cual se describe en la tabla 3, que se presenta a continuación.

Tabla 3. Prueba de homogeneidad de la varianza (prueba de igualdad de Levene de varianzas del errora)

Variable Dependiente: Tiempo de fondeo (éxito de financiamiento)

\begin{tabular}{|l|l|l|l|}
\hline $\mathbf{F}$ & Df1 & Df2 & Sig. \\
\hline 1.019 & 3 & 111 & .387 \\
\hline
\end{tabular}

Prueba la hipótesis nula que la varianza de error de la variable dependiente es igual entre grupos.

Diseño: Interceptación + Montrec + Plazo + Tasint + Fond + Ries

Fuente: Elaboración propia usando IBM SPSS 22

La prueba de igualdad/homogeneidad de la varianza de Levene muestra un resultado 0.387>0.05 lo cual confirma que este supuesto no ha sido violado, por lo tanto, no se rechaza la hipótesis nula de homogeneidad de varianza y se procede con la comprobación de los siguientes supuestos (Ver tabla 4).

Tabla 4. Prueba de correlación entre las variables de estudio

\begin{tabular}{|c|c|c|c|c|c|c|}
\hline & & Montrec & Plazo & Tasint & NoFond & Tiefond \\
\hline \multirow[t]{2}{*}{ Montrec } & Correlación de Pearson & 1 & .080 & -.258 & .643 & .396 \\
\hline & Sig. (bilateral) & & .396 & .005 & .000 & .000 \\
\hline \multirow[t]{2}{*}{ Plazo } & Correlación de Pearson & .080 & 1 & .268 & .077 & .341 \\
\hline & Sig. (bilateral) & .396 & & .004 & .412 & .000 \\
\hline \multirow[t]{2}{*}{ Tasint } & Correlación de Pearson & -.258 & .268 & 1 & -.217 & -.209 \\
\hline & Sig. (bilateral) & .005 & .004 & & .020 & .025 \\
\hline \multirow[t]{2}{*}{ NoFond } & Correlación de Pearson & .643 & .077 & -.217 & 1 & .098 \\
\hline & Sig. (bilateral) & .000 & .412 & .020 & & .295 \\
\hline \multirow[t]{2}{*}{ Tiefond } & Correlación de Pearson & .396 & .341 & -.209 & .098 & 1 \\
\hline & Sig. (bilateral) & .000 & .000 & .025 & .295 & \\
\hline
\end{tabular}

**. La correlación es significativa en el nivel 0,01 (2 colas). *. La correlación es significativa en el nivel 0,05 (2 colas). 
En la tabla 4, se observa que entre las covariables Montrec/Plazo, Plazo/Tasint, Plazo/NoFond, existe una correlación positiva débil; Montrec/Tasint, Tasint/NoFond muestran una correlación negativa débil y Montrec/NoFond tienen una correlación positiva moderada. La correlación entre la variable dependiente Tiefond y las covariables Montrec, Plazo, Tasint y NoFond se correlacionan sustancialmente, indicando que ninguna de las covariables está altamente correlacionada $(\mathrm{r}>\mathrm{.80})$. Profundizando en este supuesto, se comprobó la independencia de las covariables de la variable dependiente mediante el análisis de la varianza. Los resultados indican que el monto de crédito observa $\mathrm{F}=1.623(\mathrm{P}=.188)$, lo cual cumple con el criterio de independencia que se está evaluando ( $\mathrm{P}>.05)$; también el plazo de crédito $\mathrm{F}=.830(\mathrm{P}=.480)$ y el número de fondeadores $\mathrm{F}=.683(\mathrm{P}=.565$. La tasa de interés tiene como resultado una $\mathrm{F}=197.822(\mathrm{P}=.000)$ indicando una relación débil. Se continua con la comprobación de supuestos.

En la tabla 5 se describe la relación de las variables Tiefond con Ries y Montrec, Plazo, Tasint y NoFond, es decir se presenta el supuesto de homogeneidad de la regresión de la pendiente (prueba de efectos inter sujetos modelo personalizado).

Tabla 5. Supuesto de homogeneidad de la regresión de la pendiente Variable dependiente: Tiempo de Fondeo (Éxito de financiamiento)

\begin{tabular}{|l|l|l|l|l|l|}
\hline Origen & $\begin{array}{l}\text { Tipo III de suma } \\
\text { de cuadrados }\end{array}$ & Gl & $\begin{array}{l}\text { Cuadrático } \\
\text { promedio }\end{array}$ & F & Sig. \\
\hline Modelo corregido & $3854201.679 \mathrm{a}$ & 11 & 350381.971 & 19.561 & .000 \\
\hline Interceptación & 606044.460 & 1 & 606044.460 & 33.835 & .000 \\
\hline Ries & 335811.800 & 1 & 335811.800 & 18.748 & .000 \\
\hline Montrec & 1443001.425 & 3 & 481000.475 & 26.854 & .000 \\
\hline Plazo & 9575.052 & 1 & 9575.052 & .535 & .466 \\
\hline Tasint & 811295.505 & 1 & 811295.505 & 45.294 & .000 \\
\hline NoFond & 167468.971 & 1 & 167468.971 & 9.350 & .003 \\
\hline Ries $*$ Montrec * Plazo * & 101427.576 & 4 & 25356.894 & 1.416 & .234 \\
\hline Tasint * NoFond & & & & & \\
\hline Error & 1844931.921 & 103 & 17911.960 & & \\
\hline Total & 13995919.000 & 115 & & \\
\hline Total corregido & 5699133.600 & 114 & & \\
\hline \hline
\end{tabular}

Se comprueba el supuesto de homogeneidad de la regresión de la pendiente, puesto que el ratio F de interacción entre las variables Ries * Montrec * Plazo * Tasint * NoFond $\mathbf{F}=\mathbf{1 . 4 1 6}(\mathbf{P}=. \mathbf{2 3 4})$ muestra que la interacción es estadísticamente no significativa en un nivel Alpha de .05. Este supuesto se evaluó con la suma de cuadrados tipo III por ser comúnmente aceptado, con la construcción de términos tipo interacción. Es evidente que el resultado de la interacción de covariables y variable independiente no es significativa, lo que sugiere el uso de la suma de cuadrados tipo II para esta prueba de diseño factorial personalizado (Langsrud, 2003), no siendo el caso cuando el diseño de prueba de efectos inter sujetos es del tipo factorial completo. Para esta prueba se usa la suma de cuadrados tipo III pues prueba los efectos principales en presencia de las interacciones. No 
hay diferencia de resultados (Ries * Montrec ${ }^{*}$ Plazo ${ }^{*}$ Tasint $*$ NoFond $\mathbf{F}=1.416(\mathbf{P}=.234)$ al evaluar esta prueba con la suma de cuadrados tipo II y III lo que sugiere factores ortogonales.

\subsubsection{Análisis de la covarianza}

Los supuestos pertinentes han sido comprobados satisfactoriamente, dando así la pauta para realizar el análisis de la covarianza, el proceso y sus respectivos resultados se muestran a continuación (tabla 6).

Tabla 6. Pruebas de efectos inter sujetos factorial completa

Variable dependiente: Tiempo de fondeo (éxito de financiamiento)

\begin{tabular}{|c|c|c|c|c|c|c|}
\hline Origen & $\begin{array}{l}\text { Tipo III de suma } \\
\text { de cuadrados }\end{array}$ & gl & $\begin{array}{l}\text { Cuadrático } \\
\text { promedio }\end{array}$ & $\mathbf{F}$ & Sig. & $\begin{array}{l}\text { Eta parcial } \\
\text { al cuadrado }\end{array}$ \\
\hline Modelo corregidob & 3752774.103 & 7 & 536110.586 & 29.472 & 000 & .658 \\
\hline Interceptación & 856111.512 & 1 & 856111.512 & 47.064 & 000 & .305 \\
\hline Montrec & 1018379.636 & 1 & 1018379.636 & 55.985 & 000 & .343 \\
\hline Plazo & 14936.832 & 1 & 14936.832 & 821 & 367 & .008 \\
\hline Tasint & 884531.353 & 1 & 884531.353 & 48.627 & 000 & 312 \\
\hline NoFond & 128039.079 & 1 & 128039.079 & 7.039 & 009 & .062 \\
\hline Ries & 1739509.318 & 3 & 579836.439 & 31.876 & 000 & .472 \\
\hline Error & 1946359.497 & 107 & 18190.276 & & & \\
\hline Total & 13995919.000 & 115 & & & & \\
\hline Total corregido & 5699133.600 & 114 & & & & \\
\hline
\end{tabular}

a. R al cuadrado $=.658$ ( $R$ al cuadrado ajustada $=.636$ ).

b. La interceptación se incluye normalmente en el modelo

Fuente: Elaboración propia usando IBM SPSS 22

La prueba de efectos inter sujetos muestra que hay diferencia significativa entre las variables tiempo de fondeo $\{\mathrm{F}(3,107)=31.876, \mathrm{P}=.000\}$ y el riesgo, mientras se controla a los covariables montos, plazo, tasa de interés y número de fondeadores. El riesgo, es una variable significativa, explica un $47.2 \%$ de la varianza en el tiempo de fondeo; el monto es una covariable significativa, explica un $34.3 \%$ en el tiempo de fondeo; el plazo no es una covariable significativa, explica el .08\% de la varianza en el tiempo de fondeo; la tasa de interés es una covariable significativa, explica un $31.2 \%$ de la varianza en el tiempo de fondeo y el número de fondeadores es una covariable significativa, explica un $6.2 \%$ de la varianza en el tiempo de fondeo. El coeficiente de determinación indica que el $65.8 \%$ de la varianza es explicada por el modelo con un 95\% de nivel de confianza.

\subsection{Medias marginales estimadas}

La tabla 7 muestra las medias marginales estimadas de la clasificación de riesgo después de que el efecto de las covariables Montrec, Plazo, Tasint y NoFond ha sido estadísticamente removido sobre la variable dependiente tiempo de fondeo. 
Tabla 7. Estadísticos descriptivos sin ajuste y ajustados

Variable dependiente: Tiempo de fondeo (éxito de financiamiento)

\begin{tabular}{|c|c|c|c|c|c|c|}
\hline \multirow{2}{*}{$\begin{array}{l}\text { Calificación de } \\
\text { riesgo de la } \\
\text { empresa } \\
\text { solicitante }\end{array}$} & \multirow[t]{2}{*}{ Media } & $\begin{array}{l}\text { Desviación } \\
\text { estándar }\end{array}$ & \multirow{2}{*}{$\begin{array}{l}\text { Media } \\
\text { ajustada }\end{array}$} & \multirow{2}{*}{$\begin{array}{l}\text { Desviación } \\
\text { estándar }\end{array}$} & \multicolumn{2}{|c|}{ Intervalo de confianza $95 \%$} \\
\hline & & & & & $\begin{array}{l}\text { Límite } \\
\text { superior }\end{array}$ & $\begin{array}{l}\text { Límite } \\
\text { inferior }\end{array}$ \\
\hline A1 & 445.71 & 219.464 & 876.293 & 79.497 & 718.700 & 1033.886 \\
\hline A2 & 299.91 & 208.637 & 515.227 & 38.943 & 438.028 & 592.426 \\
\hline B1 & 326.96 & 215.618 & 301.374 & 19.898 & 261.929 & 340.819 \\
\hline B2 & 73.27 & 124.189 & -286.253 & 60.457 & -406.102 & -166.404 \\
\hline
\end{tabular}

a. Las covariables que aparecen en el modelo se evalúan en los valores siguientes: Monto del crédito en diez miles de pesos (MXP) = 33.6712; Plazo del crédito en horas $=14124.52$; Tasa de interés para la empresa fondeada $=.1212$, Número de fondeadores $=162.12$.

Fuente: Elaboración propia usando IBM SPSS 22

La media ajustada para la calificación de riesgo de la empresa solicitante A1 (876.293) muestra que es efectivamente una de las calificaciones más seguras a la hora que los inversionistas deciden colocar su capital en algún proyecto, aunque esto no representa la mejor rentabilidad por la inversión de alguna forma puede garantizar el retorno de esta. De la misma manera, la calificación de riesgo de la empresa solicitante B2 (-286.253) indica que el riesgo es considerablemente mayor para los fondeadores, lo que intrínsecamente se relaciona con un mejor rendimiento.

\subsection{Análisis a posteriori}

Una vez realizado el análisis de la covarianza, se determinó que existe una diferencia significativa en la variable independiente, el contraste de hipótesis se llevó a cabo mediante una matriz L, personalizando cada prueba para dar respuesta a estas. El análisis a posteriori (comparación por parejas) para dilucidar que grupos son los que difieren en esta variable se presenta en la tabla 8.

Tabla 8. Comparación por parejas

Variable dependiente: Tiempo de fondeo (éxito de financiamiento)

\begin{tabular}{|c|c|c|c|c|c|c|}
\hline \multirow{2}{*}{$\begin{array}{l}\text { (I) Calificación de riesg } \\
\text { de la empresa } \\
\text { solicitante }\end{array}$} & \multirow{2}{*}{$\begin{array}{l}\text { (J) Calificación de riesg } \\
\text { de la empresa } \\
\text { solicitante }\end{array}$} & \multirow[t]{2}{*}{$\begin{array}{l}\text { Diferencia de } \\
\text { medias (I-J) }\end{array}$} & \multirow[t]{2}{*}{$\begin{array}{l}\text { Error } \\
\text { estándar }\end{array}$} & \multirow[t]{2}{*}{ Sig.b } & \multicolumn{2}{|c|}{$\begin{array}{l}95 \% \text { de intervalo de } \\
\text { confianza para diferenciab }\end{array}$} \\
\hline & & & & & \begin{tabular}{|l} 
Límite \\
inferior
\end{tabular} & $\begin{array}{l}\text { Límite } \\
\text { superior }\end{array}$ \\
\hline \multirow[t]{3}{*}{ A1 } & A2 & 368.430 & 63.736 & .000 & 196.969 & 539.891 \\
\hline & B1 & 589.115 & 85.183 & .000 & 359.958 & 818.273 \\
\hline & $\overline{B 2}$ & 1201.792 & 131.197 & .000 & 848.851 & 1554.733 \\
\hline \multirow[t]{3}{*}{ A2 } & A1 & -368.430 & 63.736 & .000 & -539.891 & -196.969 \\
\hline & B1 & 220.686 & 46.273 & .000 & 96.204 & 345.167 \\
\hline & B2 & 833.362 & 94.227 & .000 & 579.876 & 1086.848 \\
\hline \multirow[t]{3}{*}{ B1 } & A1 & -589.115 & 85.183 & .000 & -818.273 & -359.958 \\
\hline & A2 & -220.686 & 46.273 & .000 & -345.167 & -96.204 \\
\hline & B2 & 612.676 & 62.516 & .000 & 444.498 & 780.855 \\
\hline
\end{tabular}


Variable dependiente: Tiempo de fondeo (éxito de financiamiento) Continuación...

\begin{tabular}{|c|c|c|c|c|c|c|}
\hline \multirow{2}{*}{$\begin{array}{l}\text { (I) Calificación de riesgo } \\
\text { de la empresa } \\
\text { solicitante }\end{array}$} & \multirow{2}{*}{$\begin{array}{l}\text { (J) Calificación de riesg } \\
\text { de la empresa } \\
\text { solicitante }\end{array}$} & \multirow{2}{*}{$\begin{array}{l}\text { Diferencia de } \\
\text { medias (I-J) }\end{array}$} & \multirow[t]{2}{*}{$\begin{array}{l}\text { Error } \\
\text { estándar }\end{array}$} & \multirow[t]{2}{*}{ Sig.b } & \multicolumn{2}{|c|}{$\begin{array}{l}95 \% \text { de intervalo de } \\
\text { confianza para diferenciab }\end{array}$} \\
\hline & & & & & \begin{tabular}{|l} 
Límite \\
inferior
\end{tabular} & $\begin{array}{l}\text { Límite } \\
\text { superior }\end{array}$ \\
\hline \multirow[t]{3}{*}{ B2 } & A1 & -1201.792 & 131.197 & .000 & -1554.733 & -848.851 \\
\hline & A2 & -833.362 & 94.227 & .000 & -1086.848 & -579.876 \\
\hline & B1 & -612.676 & 62.516 & .000 & -780.855 & -444.498 \\
\hline
\end{tabular}

Se basa en medias marginales estimadas.

*. La diferencia de medias es significativa en el nivel .05.

b. Ajuste para varias comparaciones: Bonferroni.

Fuente: Elaboración propia usando IBM SPSS 22

Se observa que existe diferencia significativa entre las clasificaciones de riesgo A1 y A2 $(\mathrm{P}=.000), \mathrm{A} 1$ y B1 (P=.000), A1 y B2 (.000), A2 y B2 (.000) Y B1 y B2 (.000), indicando toma de decisiones por parte de los inversionistas en el momento de colocar su capital en un proyecto u otro. Finalmente, la potencia estadística tiene como resultado 1>.80 lo que significa que lo que se ha encontrado se puede extrapolar a la población, el tamaño del efecto evaluado tiene como resultado $1.0408330>.40$ en la escala de Cohen, lo que muestra un efecto grande, además de indicar que el riesgo del proyecto representa el $28.52 \%$ de la varianza total del éxito de fondeo.

\section{Hallazgos}

Las Pymes en México presentan un acceso limitado al financiamiento bancario, derivado de altas tasas de interés, falta de garantías, información financiera escasa, y alta mortandad de las mismas, de esta manera el autofinanciamiento y el crédito vía proveedores representan las opciones de mayor uso para el fondeo de las Pymes en México, situación que coloca al sector de financiamiento a Pymes en México por debajo de países como Chile, Panamá, Brasil y Costa Rica, considerando solamente la región de América Latina.

La industria mexicana de crowdfunding presenta un esquema de crecimiento acelerado, prueba de ello es el incremento constante en el monto fondeado por las diferentes plataformas. Para los emprendedores, el surgimiento del fondeo colectivo representa una alternativa válida de solución en la búsqueda de financiamiento, y para los fondeadores constituye una opción rentable de inversión a niveles de riesgo aceptables, derivado de la regulación y formalización del sector de las finanzas tecnológicas en México, lo que brinda mayor transparencia y confiabilidad al ecosistema Fintech. En esta misma línea las plataformas de Crowdfunding tienen una propuesta de valor basada en la accesibilidad derivada de la amplia penetración, y el uso generalizado de las tecnologías de información y comunicación mediante dispositivos electrónicos, lo que favorece la inclusión financiera en lo general, y el acceso al crédito de la micro, pequeña y mediana empresa.

Del análisis de la literatura relativa al fondeo de Pymes, y sus principales características destacan la calificación del riesgo, el monto del préstamo, la duración de crédito, la tasa de retorno, y 
el número de fondeadores (para el caso del Crowdfunding), como indicadores transcendentales en la obtención de financiamiento para Pymes. La calificación del riesgo es relevante en dos sentidos, tanto para la fijación de la tasa ajustada al nivel de incertidumbre en los retornos de los créditos otorgados, como en la selección y asignación de los recursos. El monto, y la duración del préstamo están asociados al tamaño de la empresa, y la tasa de interés esta interrelacionada al nivel de riesgo crediticio. Por otro lado, el número de fondeadores se vincula en mayor medida al nivel de riesgo y la tasa de retorno.

Dentro del análisis del éxito de fondeo (medido en horas) realizado a Pitchbull se encontró que el riesgo es la variable de mayor significancia, ya que explica el $47.2 \%$ de la varianza en el éxito de fondeo, para el caso de estudio se encontró que los fondeadores priorizan el retorno de los fondos sobre cualquier otra variable, así mismo el monto explica un $34.3 \%$ en el éxito de fondeo, ya que proyectos con menores requerimientos de capital logran financiarse en menor tiempo al requerir un menor número de fondeadores, por ende dicha variable explica solamente un $6.2 \%$ de la varianza en el éxito de fondeo. La tasa de retorno es una covariable significativa que explica un $31.2 \%$ en el tiempo de fondeo debido a que los prestamistas esperan obtener el mejor retorno posible a niveles bajos y moderados de riesgo, el plazo del crédito es una variable poco significativa debido a que explica sólo el .08\% de la varianza en el éxito de fondeo, lo que denota que para los prestamistas un retorno a corto plazo no es una prioridad.

\section{Conclusiones}

Para los emprendedores, las Pymes, y los participantes del ecosistema emprendedor, el surgimiento del fondeo colectivo representa una solución a las grandes carencias de financiamiento en México, para los inversionistas o fondeadores (bajo la normatividad de la Ley Fintech aprobada en 2018), constituye un parteaguas en cuanto a la relación riesgo-rendimiento de la oferta existente en el sistema financiero mexicano, participando en un sector de las finanzas tecnológicas con altas tasas de crecimiento en un esquema formal, transparente y confiable.

El objetivo del presente trabajo es identificar el grupo de variables que impactan en el éxito de financiamiento para Pymes a través del fondeo colectivo en la plataforma Pitchbull, una vez aplicado el modelo, el análisis y estudio de los datos se rechaza la hipótesis nula Ho $\mathbf{H}_{1}$ debido a que se encontraron diferencias significativas en el éxito de financiamiento de las empresas que buscan fondos por medio de la plataforma objeto de estudio, en función del nivel de riesgos de los proyectos, y controlando el efecto de las variables de monto, plazo, tasa de interés, así como del número de fondeadores. Por otro lado, las medias marginales de tiempo de fondeo ajustadas del efecto de las covariables indican que las empresas con la calificación de riesgo más baja (B2, y B1) son las primeras en fondearse, seguidas de las empresas con mejores calificaciones de riesgo (A1, y A), lo cual se explica debido a que la tasa de interés ganada por fondear empresas con mayor riesgo (B2) se duplica con respecto a las empresas de mejor calidad crediticia (A1). A partir de estas medias ajustadas, está claro que los proyectos con la calificación crediticia más baja (B2) tienen un mejor impacto en el éxito de fondeo, seguido de aquellas con calificaciones B1, A2 y A1 respectivamente. Así también, con base en la prueba omega cuadrada $\left(\omega^{2}\right)$ del tamaño del efecto, el riesgo del proyecto representan el $28.52 \%$ de la varianza total del éxito de fondeo, dando muestra de que el éxito de fondeo puede ser explicado por el nivel de riesgo, y está controlada de forma significativa por el efecto del monto del 
crédito, número de fondeadores, la tasa de retorno, y el plazo del crédito, es de destacar que las variables utilizadas en el presente trabajo se consideraron en función de su disponibilidad, sin embargo otros factores que pueden influir en el éxito del fondeo son: edad, género, nivel de ingresos, ocupación, nivel de educación, estado civil, costos de transacción, métodos de reembolso, y sector de la empresa entre otros.

Por otro lado, una de las limitaciones de la técnica de análisis de covarianza (ANCOVA) es el cumplimiento de la heterogeneidad de los coeficientes de regresión, debido a que muchas de las relaciones entre las variables dependientes y las covariables son lineales o aproximadamente lineales, por ello, algunas alternativas a estas limitaciones son la estratificación (Blocking) que consiste en asignar a los sujetos a grupos definidos por ciertos rangos de las puntuaciones de las covariables, así mismo el reemplazo de las condiciones experimentales con la covariable permite emplear sólo la covariable para predecir las puntuaciones de las variables dependientes.

Con respecto a la problemática social se encontró que las alternativas de financiamiento a las fuentes tradicionales que actualmente existen en pro de la pequeña y mediana empresa son limitadas, pero en constante expansión. Estas empresas tienen que enfrentarse a distintos problemas para poder mantenerse en operaciones siendo las principales: la restricción de acceso a fuentes de financiamiento, altas tasas de interés, y cuantiosas garantías. En México, aproximadamente la mitad de la población en edad de trabajar esta excluidos del sistema financiero formal, sobre todo en zonas rurales, suburbanas, y urbanas en pobreza, se estima que cerca del 60\% de los adultos en México carecen de una cuenta bancaria en una institución financiera formal, dicha exclusión provoca que los sectores con menores ingresos paguen altísimos costos por los servicios financieros a los que acceden casi siempre de forma informal. En dicho contexto, las iniciativas en Finanzas Tecnológicas representan soluciones viables a los problemas de exclusión debido a que en México viven 80.6 millones de usuarios de internet, y 86.5 millones de usuarios de teléfonos celulares para quienes el desarrollo de soluciones FinTech impacta positivamente. En cuanto al acceso de créditos por parte de las Pymes, el uso de plataformas tecnológicas ha permitido incrementar el financiamiento a miles de ellas, inclusive para empresas sociales enfocadas en el arte, la cultura, o la salud, También, puede impulsar la igualdad de oportunidades en cuanto a edad, género, y nivel socioeconómico ya que para muchos usuarios implica su primer acceso al crédito empresarial de manera formal, y a un costo accesible. Por el lado de los fondeadores de las plataformas de fondeo colectivo, estos tienen la oportunidad de obtener retornos superiores a niveles de riesgo aceptables, lo anterior, derivado de la base normativa estipulada en la Ley para Regular a las Instituciones de Tecnología Financiera (Ley Fintech). Otras ventajas derivadas del uso de finanzas tecnológicas son: creación de un historial crediticio, datos sólidos y transparentes, disminución del uso del dinero físico, mejores servicios en depósitos, pagos, microcréditos e incluso acceso a seguros.

Por otro lado, el estudio de las plataformas de fondeo colectivo de préstamos a nivel internacional, los últimos años han presentado un incremento importante en la literatura referente a fondeo colectivo de préstamos, a 2018, la base de datos ISI Web of Knowledge mostraba 90 artículos científicos relativos a este tema, de los cuales el 55\% proceden de Estados Unidos, China, e Inglaterra. Respecto a las plataformas las más analizadas son: Prosper.com, Kiva.org, y Kickstarter.com, en temas relativos a incumplimiento, discriminación, confiabilidad, capital de riesgo, modelos 
operativos de fondeo colectivo, riesgo, regulación, requerimientos de crédito, requerimientos de capital, comportamiento irracional, y factores de éxito de fondeo. La presente investigación se une a los estudios relativos al éxito de fondeo desde el análisis del impacto del nivel de riesgo presentado a los fondeadores, sin embargo, futuras investigaciones debieran considerar los impactos de la naturaleza intrínseca de las empresas, a las variables estudiadas, y en función de plataformas internacionales.

El presente trabajo busca fortalecer el marco de conocimiento de las finanzas tecnológicas en lo general y del fondeo colectivo de préstamos en lo particular, en un sector en auge que pretende aliviar de una manera novedosa e incluyente la falta de financiamiento al ecosistema emprendedor, se considera que las aportaciones presentadas pueden contribuir a una mejor toma de decisiones en la estructura de fondeo de las pequeñas y medianas empresas.

\section{Referencias}

[1] Atieno, R. (2001). Formal and informal institutions lending policies and access to credit by small-scale enterprises in Kenya. Nairobi, Kenya: And empirical Assessment. AERC Research

[2] Paper 111, African Economic Research Consortium, Nairobi, November 2001.

[3] Ballell, T. (2013). El crowdfunding: una forma de financiamiento colectiva, colaborativa y participativa de proyectos. Pensar en derecho, 3, 101-123.

[4] Banco de México (2014). Resultados de la Encuesta de Evaluación Coyuntural del Mercado Crediticio. Cuarto Trimestre de 2013. Comunicado de Prensa, 20 de febrero. México: Banco de México.

[5] Banco de México (2015). Reporte sobre las condiciones de competencia en el otorgamiento de crédito a las pequeñas y medianas empresas (PYME) crédito a PYMES. Ciudad de México: Banco de México.

[6] BBVA (2015). Crowdfunding: una alternativa financiera para emprendedores e inversionistas. Madrid: Banco Bilbao Vizcaya Argentaria, centro de innovación.

[7] BBVA (2016). Los cuatro tipos de crowdfunding más útiles para financiar tu PYME, 1-9. Recuperado a partir de http://www.bbvacontuempresa.es/a/los-cuatro-tipos-crowdfunding-mas-utiles-parafinanciar-tu-pyme

[8] Bean, M. (2017). Determinants of Interest Rates. Education and Examination Committee of the Society of Actuaries. Financial Mathematics Study Note. Recuperado de: https://soa.org/globalassets/assets/Files/Edu/2017/fm-determinants-interest-rates.pdf

[9] Benchimol, J. (2013). Risk aversion in the Eurozone. Research in Economics, 68 (1) 39-56. https://doi.org/10.1016/j.rie.2013.11.005

[10] Berger, A., and Udell, G. (2002). Small business credit availability and relationship lending: The importance of bank organizational structure. The Economic Journal, 112 (February), F32-F53. https://doi.org/10.2139/ssrn.285937

[11] Besanko, D. and A. V. Thakor. (1987). Collateral and Rationing: Sorting Equilibria in Monopolistic and Competitive Credit Markets. International Economic Review, 28(3): 671-689. https://doi.org/10.2307/2526573

[12] Boot, A.W.A., A.V. Thakor, and G.F. Udell. (1991). Secured Lending and Default Risk: Equilibrium Analysis, Policy Implications and Empirical Results. The Economic Journal 101, 458-472. https://doi.org/10.2307/2233552

[13] Brighi, P. and Venturelli, G. (2017). Demand and Supply Determinants of Credit Availability: Evidence from the Current Credit Crisis for European SMEs. In: Chesini G., Giaretta E., Paltrinieri A. (eds) Financial Markets, SME Financing and Emerging Economies. Palgrave Macmillan Studies in Banking 
REMEF (The Mexican Journal of Economics and Finance)

Factores de éxito en el financiamiento para Pymes a través del Crowdfunding en México

and Financial Institutions. Palgrave Macmillan, Cham.pp.41-70. https://doi.org/10.1007/978-3-31954891-3_4

[14] Bruhn, M., and Love, I. (2014). The real impact of improved access to finance: Evidence from Mexico. Journal of Finance, 69(3), 1347-1376. https://doi.org/10.1111/jofi.12091

[15] Cahn, C., Grotto, M., Salvadè, F. (2018). External Credit Rating and Bank Lending, Banque de France, Working Paper 691. Banque de France. https://publications.banquefrance.fr/sites/default/files/medias/documents/wp-691.pdf

[16] Calvo, A. y Jacynycz, V. (2015). Desarrollo de una plataforma de crowdfunding distribuida sobre Ethereum, Trabajo de Fin de Grado en Ingeniería del Software Madrid: Universidad Complutense de Madrid, España.

[17] Camacho, J. y Delgado, J. (1996). Obligaciones (5a ed.). Bogotá: Pontificia Universidad Javeriana.

[18] Capizzi, V. and Carluccio, E. (2016). Competitive Frontiers in Equity Crowdfunding: The Role of Venture Capitalists and Business Angels in the Early-Stage Financing Industry, in Bottiglia and Pichler (eds.), Crowdfunding for SMEs: A European Perspective. 117-157. London: Palgrave Macmillan Studies in Banking and Financial Institutions. https://doi.org/10.1057/978-1-137-56021-6_6

[19] Chan S. and Kanatas G. (1985). Asymmetric valuation and the role of collateral in loan agreements. Money Credit Bank, 17(1):85-95. https://doi.org/10.2307/1992508

[20] Chandler, M. (2016). Economy Watch. Recuperado el 10 de octubre de 2019, de https://www.economywatch.com/mutual-funds/definition/asset-size.html

[21] Chen, J. (2010). Essentials of Technical Analysis for Financial Markets. New Yersey: John Wiley \& Sons. https://doi.org/10.1002/9781119204213

[22] Cohen, M. y Baralla, G. (2012). La situación de las PyME en América Latina. Argentina: IrealPyME.

[23] Cole RA, Goldberg LG, White LJ (2004) Cookie-cutter versus character: the micro structure of small business lending by large and small banks. Journal of Financial Quantitative Analisis, 39(2):227-251. https://www.jstor.org/stable/30031854

[24] CONAIF (2018). Reporte Nacional de Inclusión Financiera. Ciudad de México: Consejo Nacional de Inclusión Financiera.

[25] Cuesta, C., Roibas, I., Rubio, A., Ruesta, M., Tuesta, D., y Urbiola, P. (2014). Crowdfunding en 360o: alternativa de financiamiento en la era digital. Recuperado a partir de https://www.bbvaresearch.com/wp-content/uploads/2014/10/Observatorio-crowdfunding-vf.pdf.

[26] Cuñat, V. and García-Appendini, E. (2012). Trade credit and its role in entrepreneurial finance. In: Cumming, D. (Ed.), 2012, Oxford Handbook of Entrepreneurial Finance, Oxford University Press, New York, pp. 526-557. https://doi.org/10.1093/oxfordhb/9780195391244.001.0001

[27] De Vincentiis P., Culasso F. and Cerrato S. (2019). The Future of Risk Management, Volume I. Palgrave Macmillan, Springer Nature Switzerland. https://doi.org/10.1007/978-3-030-14548-4

[28] DOF (2018). Disposiciones de carácter general aplicables a las instituciones de tecnología financiera. Recuperado el 28 de noviembre de 2018, a partir de https://www.dof.gob.mx/nota_detalle_popup.php?codigo=5537450

[29] Ekpu, V. (2016). Determinants of Bank Involvement with SMEs. Springer Briefs in Finance. In: SupplySide Factors Affecting Bank Lending to SMEs. https://doi.org/10.1007/978-3-319-25837-9_5

[30] Fenton, R. y Padilla, R. (2012). Financiamiento de la banca comercial a micro, pequeñas y medianas empresas en México. México: Naciones Unidas-Cepal, Comisión Nacional Bancaria y de Valores. https://doi.org/10.18356/2f365699-es

[31] Fiedler, E. (1971). Measures of Credit Risk and Experience. Massachusetts, Cambridge: NBER. https://www.nber.org/books/fied71-1 
[32] Finnovista. (2019). El ecosistema Fintech mexicano recupera el liderazgo en América Latina y se acerca a la barrera de las 400 startups. Finnovista. Recuperado el 1 de junio de 2019, a partir de https://www.finnovista.com/actualizacion-fintech-radar-mexico-2019/.

[33] Finnovista and BID. (2019). El ecosistema Fintech de Colombia consolida su estado de madurez y su posición como el tercer mayor ecosistema Fintech de la región. Recuperado el 28 de abril de 2020, a partir de https://www.finnovista.com/fintech_radar_colombia_2019/

[34] Goldstein, E. (2011). El crédito a las pymes en la Argentina: Evolución reciente y estudio de un caso innovador. Santiago de Chile: Naciones Unidas, Cepal, Aecid.

[35] Hauswald, R. and Márquez, R. (2003). Information technology and financial services competition. The Review of Financial Studies, 16 (3), 921-948. https://doi.org/10.1093/rfs/hhg017

[36] HM Treasury (2004). Management of Risk - Principles and Concepts. The Orange Book.United Kingdom: Controller of Her Majesty's Stationery Office. https://www.who.int/management/general/risk/managementofrisk.pdf

[37] INEGI (2015) Encuesta Nacional sobre Productividad y Competitividad de las Micro, Pequeñas y Medianas Empresas (ENAPROCE) - Encuestas en Establecimientos. Recuperado a partir de http:www.inegi.org.mx/est/contenidos/proyectos/encuestas/establecimientos/otras/enaproce/default.aspx.

[38] Jacoby, N., Saulnier, R. and McFerrin, J. (1942). Term Lending to Business. Recuperado de: http://www.nber.org/books/jaco42-1. https://doi.org/10.2307/1052549

[39] Jaffee, D., and Russell, T. (1976) Imperfect information, uncertainty, and credit rationing. The Quarterly Journal of Economics 90 (4): 651-666. https://doi.org/10.2307/1885327

[40] Jimenez, G., Salas-Fúmas, V. and Salas, J. (2006) Determinants of collateral. Journal Financial Economics 81:255-281. https://doi.org/10.2139/ssrn.565343

[41] Joseph, C. (2013). Advanced credit risk analysis and management. John Wiley and Sons Ltd.

[42] Jiménez, G. and Saurina, J. (2002), Loan Characteristics and Credit Risk, Bank of Spain. DirectorateGeneral of Regulation. Recuperado de: https://www.bis.org/bcbs/events/wkshop0303/p03jimesaur.pdf

[43] Kickstarter (2019). Kickstarter. Recuperado el 2019, de https://www.kickstarter.com/projects/anomalisa/charlie-kaufmans-anomalisa.

[44] Koulafetis, P. (2017). Modern Credit Risk Management. Theory and practice. Lóndres: Palgrave Macmillan. https://doi.org/10.1057/978-1-137-52407-2

[45] Langsrud, 0. (2003). ANOVA for unbalanced data: Use Type II instead of Type III sums of squares. Statistics and Computing. 13, 163-167. https://doi.org/10.1023/A:1023260610025

[46] León, E., y Saavedra, M. L. (2018). Fuentes de financiamiento para las MIPYME en México. Revista Ciencia Administrativa, 1(2018)159-175.

[47] Martínez, A. L. (2018). ¿Quién tiene acceso al crédito en México? Discriminación por color de piel en el mercado crediticio mexicano. Tesis doctoral. Centro de Investigación y Docencia Económicas. http://hdl.handle.net/11651/2723

[48] Martínez, A., Pérez de Lema, D., y Hernández, S. (2008). El financiamiento de la PYME en Puebla (México): un estudio empírico. Revista de la Facultad de Economía, BUAP, 38 (2019) 59-80.

[49] Moro, A., Wisniewski, T. and Mantovani, G. (2017). Does a manager's gender matter when accessing credit? Evidence from European data. Journal of Banking \& Finance, 80, 119-134. https://doi.org/10.2139/ssrn.2501933

[50] Mota, J., Moreira, C. and Brandão, C. (2018), Determinants of microcredit repayment in Portugal: analysis of borrowers, loans and business projects, Portuguese Economic Journal, https://doi.org/10.1007/s10258-018-0148-2. 
[51] Mundial, B. (2017). Crédito interno al sector privado (\% del PIB)- México, Chile, Costa Rica, Colombia, Brasil, Bolivia, Panamá. Recuperado el 20 de julio de 2017, a partir de https://datos.bancomundial.org/indicador/FS.AST.PRVT.GD.ZS? contextual=default\&end=2016\&loca tions=MX-CL-CR-CO-BR-BO- PA\&start=2014\&view=chart\&year_low_desc=false

[52] Nesta (2014). Understanding Alternative Finance: The UK Alternative Finance Industry Report 2014. Nesta. Recuperado de: www.nesta.org.uk/sites/default/files/understandingalternativ e-finance2014.pdf.

[53] OCDE-CEPAL (2012). Perspectivas Económicas de América Latina 2013. Políticas de Pymes para el cambio estructural. Paris: OCDE/CEPAL. OECD Publishing.

[54] Onyango, P. (2015) The relationship between loan duration and interest rates for commercial banks in Kenya, University of Nairobi, Kenya. Recuperado de: http://erepository.uonbi.ac.ke/handle/11295/95261

[55] Ordanini, A., Miceli, L., Pizzetti, M., and Parasuraman, A. (2011). Crowdfunding: transforming customers into investors through innovative service platforms. Journal of Service Management, 22(4), 443-470. https://doi.org/10.1108/09564231111155079

[56] Pavón, L. (2010). Financiamiento a las microempresas y pymes en México (2000-2009). (CEPAL/AECID, Ed.), Financiamiento del desarrollo. 226. Santiago de Chile: Naciones Unidas.

[57] Penna, R. (2011). The NONPROFIT outcomes; A Complete Guide to Program Effectiveness, Performance Measurement, and Results. The Rensselaerville Institute. John Wiley \& Sons, Inc.

[58] Pitchbull. (2019). Pitchbull.com. Recuperado el 26 de abril de 2019, a partir de https://www.pitchbull.com/

[59] Previati, D., Galloppo, G., and Salustri, A. (2015). Crowdfunding en la Unión Europea: factores impulsores y atractivo. Papeles de Economía Española, 146, 104-120. Oai:iris.uniroma3.it:11590/292812

[60] Quero, M. y Fernández, R. (2014). Análisis de las relaciones de co-creacion de valor. Un estudio de caso de crowdfunding. Universia Business Review, 43, 128-143. https://journals.ucjc.edu/ubr/article/view/914

[61] Rodríguez, I. (2016). Está lista la ley sobre financiamiento colectivo. El Economista, 1-5. Recuperado a partir de https://www.eleconomista.com.mx/sectorfinanciero/Esta-lista-la-ley-sobrefinanciamiento-colectivo-20160830-0030.html

[62] Rodríguez, T. (2013). Crowdfunding: una forma de financiamiento colectiva, colaborativa y participativa de proyectos, 101-123. Recuperado a partir de http://www.derecho.uba.ar/publicaciones/pensar-en-derecho/revistas/3/el-crowdfunding-unaforma-de-financiacion-colectiva-colaborativa-y-participativa-de-proyectos.pdf

[63] Saavedra, M., Milla, S., y Sánchez, B. (2012). Factores que impiden el acceso al financiamiento de la MIPYME en México: el caso del estado de Querétaro. Revista Investigación en Ciencias Administrativas, 3(abril-septiembre) 11-39.

[64] Saavedra. M.L. y Saavedra, M.E. (2016). El Problema del financiamiento de la PYME y el Sistema de Garantías en México. Teuken Bidikay, 8, (enero-junio)147-170.

[65] Sánchez, A., Ríos, F., Segura, A., Pérez de Lema, D., Guijarro, A., Hernández, S. y Marín, G. (2004). Análisis Estratégico para el Desarrollo de la Pequeña y Mediana Empresa. Estado de Veracruz. Recuperado de: http://www.expertoauditoria.es/?wpfb_dl=16

[66] Schreiner, M. (2001). Seven Aspects of Loan Size. Journal of Microfinance / ESR Review: Vol. 3: Iss. 2, Article 3. Recuperado de: http://www.microfinance.com/English/Papers/Aspects_of_Loan_Size.pdf

[67] Signoriello, V. (1991). Commercial Loan Practices and Operations. New York: The Bankers Pub Co. 
[68] Smith, J. and Smith, R. (2000). Entrepreneurial finance. 2nd edition. Washington: John Wiley \& Sons Inc.

[69] Soto, O. (2001). El dinero: la teoría, la política y las instituciones. (1a ed.). México, D.F.: Universidad Nacional Autónoma de México. Facultad de Economía.

[70] Standard \& Poor (2014). Guía sobre Aspectos Fundamentales de las Calificaciones Crediticias. ¿Qué son las calificaciones crediticias y cómo funcionan? USA: Standard \& Poor's Financial Services, LLC, Mc Graw Hill Financial.

[71] Startupbootcamp, EY, IPADE. (2019). Un camino de doble sentido. La competición de instituciones financieras y Fintechs, una mirada en América Latina. Ciudad de México: Ernts and Young.

[72] Stiglitz, J. and Weiss, A. (1981). Credit Rationing in Markets with Imperfect Information. The American Economic Review, 71(3): 393-410.

[73] Sutherland, A. (2018). Does credit reporting lead to a decline in relationship lending? Evidence from information sharing technology. Journal of Accounting and Economics. Vol. 66, 1, 123-141. https://doi.org/10.1016/j.jacceco.2018.03.002

[74] Sydbank Group (2017). Credit Risk 2017. Aabenraa, Denmark: Sydbank A/S, Peberlyk.

[75] Venegas-Martínez, F. (2013). Riesgos Financieros y Económicos. Productos derivados y decisiones económicas bajo incertidumbre. 2da ed. Cengage Learning.

[76] Villalobos, J. (2012). Matemáticas Financieras. Cuarta Edición. Ciudad de México: Pearson Education. 